\title{
PLANTAR APROXIMAÇÕES: TERRÁRIOS QUE FAZEM JARDINS DE ARTETERAPIA, HORTICULTURA E GERONTOLOGIA
}

\author{
Natalia Negretti ${ }^{1}$
}

resumo

Este texto busca apresentar uma aproximação entre gerontologia e jardinagem com as áreas arteterapia e horticultura a contar de um exercício prático-teórico. A partir de oficinas de confecção de terrários realizadas em dois centros de convivência para pessoas idosas, visa uma dupla-tarefa no aproximar relações e possibilidades: estimular a atenção à presença verde por parte da instituição para que a jardinagem seja uma possibilidade de livre arbítrio de prática de usuários de tais espaços e selar os terrários como um fazer-chave entre arte e jardinagem em espaços que tenham ou não jardim.

palavras-chave

Gerontologia. Jardinagem. Terrário. Horticultura. Arteterapia.

1 Graduada em Sociologia e Política (FESPSP). Doutoranda em Ciências Sociais, pela área Estudos de Gênero, na Universidade Estadual de Campinas (Unicamp) | Bolsista CAPES (2016-2020). Especialista em Gerontologia pela Faculdade de Educação em Ciências da Saúde do Hospital Alemão Oswaldo Cruz (HAOC). Formada em Jardinagem e Recursos Paisagísticos pela Escola Municipal de Jardinagem (EMJ). E-mail: natalia_negretti@yahoo.com.br 
Pedra. Areia. Carvão. Terra. E suculentas ou cactos. Os ingredientes podem ser colocados em vidros de palmito, geleia, como também em vidros chamados de decorativos. Podem ser ainda distribuídos nessa sequência em uma garrafa pet. Após fixada à suculenta, a rega. Esta pode ser estilo a que Toquinho e Vinícius de Moraes referem na música Planta Baixa, que inicia esse relato. Por fim, pode decorar com pedras coloridas de distintos tamanhos. Podem ser também conchas, pedras de rio, areia fina, rochas; para fazer camada primeira e ou habitar mais próximo da parte da planta que vemos. Já está. Muitas possibilidades de um terrário aberto estão aí. Com esse pequeno artefato, é possível nos debruçarmos sobre relações entre quem o planta e o cria, friccionando tensões que podem também desnaturalizar dicotomias.

Emanuele Coccia (2018, p. 11) definiu as plantas como "a ferida sempre aberta do esnobismo metafísico que define nossa cultura". Em texto anterior, o filósofo ao tratar de toda forma de vida como natural e cultural, sugere que: "vida cultural e vida natural não são dois reinos separados que o homem deve juntar: são o que se produz em cada ser vivente através dos movimentos sempre cruzados do trabalho anatômico e do ecológico" (COCCIA, 2013, p. 215). Esse acerto do autor nos permite um exercício de grande valor: o de repensarmos o contato com a natureza a partir de distintas práticas e contextos.

Chamados também de minijardins, os terrários consistem em ecossistemas - e nesse sentido envolvem a relação entre seres e ambiente. "Os terrários se encaixam nessa definição porque reproduzem, em uma escala menor, o que ocorre na natureza: a camada de terra e pedriscos funciona como o solo; a água da rega, como a chuva; as as plantas, obviamente, como a vegetação" (EVANGELISTA, 2019, p. 21).

Os distintos contextos de interação com plantas durante meu curso da vida se ramificaram também em distintas práticas. Parto neste relato, contudo, dos encontros com velhices, instituições e plantas que suscitaram tanto junções quanto separações em torno de pesquisa e outras atividades envolvendo esse mesmo trio.

A contar de 2016, ano de início de uma pesquisa de doutorado com atenção a instituições voltadas ao público idoso em situação de rua ${ }^{2}$, busquei me aproximar de trânsitos e trajetórias sociais por meio da realização de uma etnografia

2 Pesquisa orientada pela Professora Doutora Isadora Lins França (Unicamp). 
que teve início numa instituição que chamo de Estação Sentinela ${ }^{3}$. Como lugar primordial da pesquisa de campo, este centro de acolhida especial para idosos (CAEI), foi um lugar-chave (FRANÇA, 2010) para a observação de relações e ambiguidades entre cuidado e controle a partir da categoria vulnerabilidade, relacionada a instituições e curso da vida nas políticas públicas gestadas em grande parte pela Secretaria Municipal de Assistência e Desenvolvimento Social (SMADS). As atribuições de sentidos de tais políticas constroem também esse lugar. As relações a contar do CAEI referido possibilitaram acompanhar a mobilidade dos interlocutores de pesquisa e acessar outros equipamentos públicos.

Na Estação Sentinela, as plantas já formavam um ponto de observação importante, conforme seu crescimento, no que referia à relação entre tempo e pesquisa, bem como influenciavam escolha dos pseudônimos dos interlocutores. Mais tarde seriam elas motivo de observação quando submetidas aos cuidados de algumas moradoras dos centros de acolhida e principalmente o lugar em processos de subjetividade no fazer da pesquisa, via fotografia e fitotipia ${ }^{4}$.

Após a formação no Curso Regular de Jardinagem e no de Recursos Paisagísticos, ambos da Escola Municipal de Jardinagem (EMJ) ${ }^{5}$, gestada pela Universidade aberta da UMAPAZ, no Parque Ibirapuera, em 2017, a vontade de trabalhar com os temas envelhecimento e plantas fora ramificada em distintas direções. Como antropóloga num curso de pós-graduação em Gerontologia, essas formações, naquele momento, influenciaram uma primeira distinção frente à jardinagem: esta como profissão e como lazer.

Como objeto de estudo, conforme a perspectiva de Silvana Tótora (2008) o envelhecimento se constitui como um problema de natureza ético-política e problematizar a velhice na contemporaneidade pode significar uma forma de comprometer-se com o combate à submissão da subjetividade, além das formas de dominação e exploração. Como na área do envelhecimento, em que há efeitos e significados de processos de diferença e desigualdade, contribuindo para uma diversidade de abordagens, políticas e ideais, o cenário social da jardinagem, como ofício e lazer, também é vasto em eixos de diferenciação e hierarquias.

3 Pseudônimo.

4 A fitotipia é uma técnica de reprodução de imagens em folhas vegetais.

5 A Escola Municipal de Jardinagem (EMJ) foi criada em 1975 como instituição voltada à formação de trabalhadores de jardinagem da Prefeitura de São Paulo. Expandiu a formação a demais interessados e manteve a gratuidade de todos os cursos relacionados à jardinagem, paisagismo e meio ambiente. Em 2009 a EMJ foi incorporada à UMAPAZ, órgão gestor da Política Municipal de Educação Ambiental. 
A jardinagem como ofício e suas implicações no envelhecimento e vice-versa, puderam ser conhecidas graças a Mandacaru e Tales ${ }^{6}$, interlocutores de uma pesquisa apresentada como trabalho de conclusão de curso de especialização em Gerontologia. A pesquisa analisou a relação entre experiências de envelhecimento e pertencimento social a partir da perspectiva de trabalhadores nas áreas verdes, cuja atividade prática é a manutenção de praças e parques na cidade de São Paulo, e a relação entre envelhecimento e jardinagem tangenciados por emoções e compreensões de qualidade de vida ${ }^{7}$. Importante apresentar que Mandacaru e Tales, com frequência ao longo de suas trajetórias profissionais, consecutivamente às atividades com registro em carteira de trabalho exerceram a profissão também como jardineiros particulares. Mandacaru, após se aposentar continuou praticando o ofício como autônomo. Foi muito por suas reflexões sobre as plantas nos jardins residenciais nos quais trabalhava, criava, e montava que as dimensões de poder sobre cuidar de jardim e ter jardim particular puderam ser compreendidas. Os jardins dos outros foram fundamentais também para um crescimento de meu interesse reflexivo nas subjetividades das relações com plantas e dimensões de intimidade de jardins.

A interlocução com ambos foi fundamental para uma perspectiva acerca de gerações, velhices e a jardinagem desde a articulação de eixos de diferenciação, contemplando no olhar a dimensão das relações de trabalho como profissão e área, bem como subjetividades e emoções. A análise de tais temáticas na teia da jardinagem como ramo profissional a espiralou. Os campos subjetivos, emocionais e de poder passaram a compor perguntas e busca analítica também na jardinagem como lazer.

A minha perspectiva como pesquisadora e profissional se modificou também com experiência de ministrar oficina de terrários com grupos de idosos. Dito de outro modo, o lazer começou a ser observado e reflexionado junto dos dois percursos: de pesquisa e de oficina. É sobre esta perspectiva e a partir deste destrinchar lazer que busco me debruçar neste trabalho: um traçado sobre relações possíveis entre gerontologia, jardinagem, arteterapia e horticultura.

Deste modo, não procuro considerar a construção de terrários uma prática exclusiva de arteterapia ou horticultura, mas me detenho, como intenção, em mostrar como estes artefatos podem ser terrenos para estas áreas e meio delas, bem como constroem, junto com os locais e circunstâncias em que são produzidos, possibilidades de reflexões. Destarte, os conceitos e diálogos aqui

\footnotetext{
6 Psedudônimos.

7 Pesquisa orientada pela Professora Doutora Silvana Tótora (PUCSP).
} 
trazidos são importantes por marcarem não somente as oficinas, como a leitura realizada em torno delas; consequentemente, também atravessam este relato.

Trago essa introdução porque penso que, em grande medida, ministrar as oficinas de terrários configurou uma experiência de arteterapia, no sentido de me aproximar de uma afetação (FAVRET-SAADA, 2005) com esta área. Como ponto de partida, tomo a reflexão de Deolinda Fabietti. A autora mostra que

em que pesem suas diversas linhas e correntes, o que tipifica a arteterapia é o fato de ela oferecer subsídios para que os sujeitos desenvolvam, durante o processo, um olhar que permita a adoção de novas posturas e a ressignificação da vida, dedicando-se à construção de uma existência gratificante (FABIETTI, 2004, p. 15).

Como mostra também a autora, a arteterapia passou por uma grande expansão a contar da relação entre arte e psiquiatria. Desenvolvida por outras áreas e vínculos entre estas, é possível, no destaque de um determinado contexto de velhices - quando institucionalizada e entrecruzada com arte e gerontologia. Ainda nesse sentido, uma ponte considerável entre psiquiatria e velhice pode estar circunscrita pelo atravessamento do espaço institucional. Nise da Silveira (2006), ao considerar o afeto como fator terapêutico em práticas, conferiu à jardinagem como uma destas: "O afeto foi fator constante na nossa seção de terapêutica ocupacional, não só na pintura, mas também na encadernação, marcenaria, jardinagem, costura, tapeçaria, etc." (SILVEIRA, 2006, p. 143).

A horticultura, definida como "ciência que trata do cultivo de diversos tipos de plantas, sejam elas cultivadas em jardins, pomares, hortas ou estufas" (SEBRAE-BAHIA, 2017, p. 6) em que a utilização de plantas "suprem dois tipos de necessidade humana: a alimentação e a estética" (idem), é olhada aqui sob a perspectiva de interações e cuidados, aproximando-se ainda de uma noção em torno de necessidade humana e do que Joaquim Almeida Cunha, Isabel Mourão, Luisa Moura e Miguel Brito apresentaram como horticultura social e terapêutica (HST): "a horticultura social e terapêutica (HST), entre outros, situa-se na prestação de cuidados a idosos, com atividades interativas e multifuncionais de trabalho/cuidado" (CUNHA; MOURÃO; MOURA; BRITO, 2017, p. 29). Ao identificarem potencialidades e a considerarem uma tecnologia, Thaís Sampaio de Souza e Marlene Barreto Santos Miranda (2017) sugerem que a Horticultura Terapia seja incorporada "às Práticas Integrativas e Complementares (PICs), no intuito de fortalecer as redes que propõem um espaço para produção alternativa de saúde, onde o sujeito é protagonista e produtor da sua saúde" (DE SOUZA; MIRANDA, 2017, p. 320). 
Se os olhos devolvem para nós o mundo em sua imagem visual, concebido como paisagem, então do mesmo modo os ouvidos revelam uma paisagem sonora, a pele uma paisagem tátil, o nariz uma paisagem olfativa, e assim por diante. É claro que, na realidade, o ambiente que as pessoas habitam não é dividido por caminhos sensórios pelos quais elas podem acessa-lo. É o mesmo mundo, não importa o caminho que escolham. Mas essas múltiplas 'paisagens' não se referem ao mundo prática e produtivamente habitado. Elas se referem aos mundos virtuais criados pela captura das experiências encorporadas [...] (INGOLD, 2014, p. 2).

As Oficinas Sobre nossos quintais: confecção de terrários, realizadas desde o início de 2019, foram alinhavadas pelo estimular da memória no que refere afeto e plantas e pela história dos terrários. O nome das oficinas fora pensado como alusão à dimensão coletiva e individual que as plantas podem nos trazer em sua presença e ausência nos ambientes, assim como a memória e imaginário, conceito este distinto do de imaginação e de ilusão além de multidisciplinar. Comprometido com real e não realidade, para Silas Guerriero é:

Constituído e expresso por símbolos [...] não se trata de uma transposição através de imagens de uma realidade externa, mas de uma construção interpretativa desta. Nunca apreendemos a realidade em sua forma pura [...] o real é fruto da interpretação dos humanos sobre a realidade exterior [...] o imaginário é o espaço da liberdade, em que novas relações e interpretações são criadas a cada momento, transformando esse real já interpretado (GUERRIERO, 2001, p. 99-100).

Figura 1 - Oficina sobre nossos quintais: confecção de terrários.

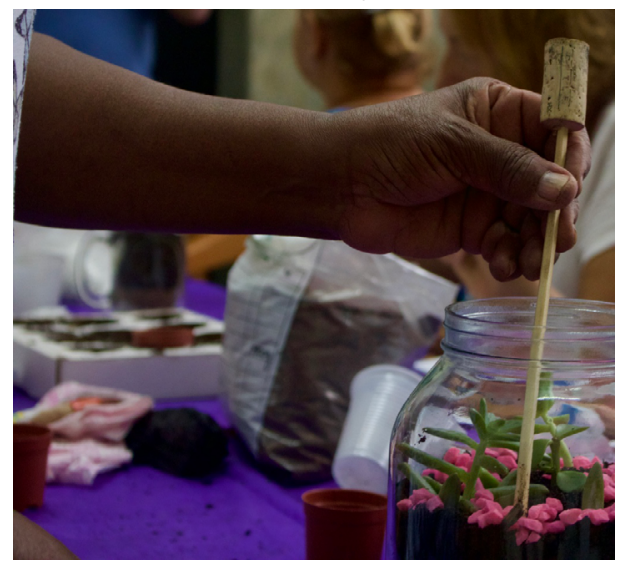

Foto: Natalia Negretti. 
Já realizada em outros espaços, como parques, igrejas e Universidade Aberta para a Terceira Idade ${ }^{8}$, esta oficina foi conseguida na Estação Sentinela. Houve uma conversa antes da realização da primeira oficina, que se deu a partir de uma chamada pública dum evento cultural voltado à população idosa. Entre o envio da inscrição e a data na qual a oficina iria acontecer, tive uma conversa com a psicóloga da Estação Sentinela sobre a produção coletiva de terrários. Por alguns motivos relatados como, por exemplo, as regras de guarda de pertences e divisão de quartos, a conversa não foi para frente. Penso que em grande medida esse foi um dos motivos de pensar tais oficinas também em instituições. Tal especificidade em torno do que fazer com o terrário alude não somente diferenças e desigualdades que atravessam essas oficinas; indica também quem pode fazer.

Politicamente trabalhar, a partir dessa atividade, com outros grupos de idosos foi a possibilidade encontrada, mas que não encerra outras tentativas. Ademais, a não permissão na Estação Sentinela, que possui tamanha especificidade, e com a qual eu tinha vontade de efetivar a oficina, foi propulsora. Foi tanto o que gerou vontade de continuar a tentar a realização nela e em outros CAEI (bem como em outras instituições voltadas à moradia de pessoas idosas - tendo em vista a diversidade destes espaços, impressa também no molde público ou privado e ainda em suas modalidades, como República e Instituições de Longa Permanência) quanto de conhecer outros grupos a partir das oficinas e refletir sobre estas em distintos lugares.

Atentar-me-ei aqui em duas oficinas. Estas constituíram vivências que, de uma maneira mais intensa, foram o estímulo para este manuscrito conforme o caráter comum dos espaços em que foram realizadas: centro de convivência para pessoas idosas. Tais instituições, uma delas em São Paulo e outra em Taboão da Serra circunscrevem, nesse sentido, uma interação anterior e frequente do grupo no próprio espaço em que foram realizadas. É preciso dizer que como centros de convivência estes espaços não contemplavam moradia. Entretanto, não deixam de se aproximar de espaços de rotina. Ambas as oficinas tiveram duração de duas horas e apenas um encontro.

Na oficina paulistana a atividade mencionada foi circunscrita a um evento cultural em que várias atividades foram oferecidas a espaços e serviços voltados ao público idoso. Quanto à oficina taboanense, fui convidada por Calêndula', quem conheço de uma pesquisa realizada em 2010 com um grupo

8 Pouco tempo antes do período da pandemia seria realizado, em Uma Universidade Aberta para a Terceira Idade, um conjunto de oficinas: com minijardins (ou terrários abertos) e terrários fechados. Esse conjunto traria mais possibilidades de prática e de reflexão; ainda é instigante.

9 Pseudônimo. 
de convivência de idosos pertencente a uma Igreja Católica em São Paulo. No retorno quase dez anos depois, ao oferecer tal oficina no mesmo grupo - mais uma vez por intermédio de minha tia Dalva, catequista em tal instituição e que acompanha o grupo há anos - reencontrei Calêndula que participou da Oficina na paróquia e, posteriormente, sugeriu o projeto em outro grupo que também frequentava. No que refere a implicações subjetivas de afeto-prática, importante mencionar tal rede, inclusive temporal e espacial, também por Calêndula convidar e estar na oficina realizada no município em que cresci e que ela vive.

Como o quintal de cada um, o destes espaços também foi fator de diferença entre as oficinas. Compreendo assim que o espaço do jardim e ou horta nas instituições e ou a presença de plantas são tanto fundamentais quanto fundantes de possibilidades para atividades de terrários e interações de grupos com as plantas. As duas instituições tinham condições bem distintas no que refere ao contato com materiais da jardinagem, como terra e areia: enquanto a instituição de São Paulo continha em sua estrutura arquitetônica um espaço pequeno com vasos, na de Taboão da Serra havia uma horta e pequenos jardins distribuídos pelo terreno. Embora ambas as oficinas tenham ficado restritas ao cultivo de terrários em recipientes, em Taboão, a presença de alguns materiais da jardinagem presentes na horta do Centro de Convivência e não trazidos por mim deixaram os participantes mais à vontade. Nesse sentido, tal presença paisagística teve efeito de diferença na oficina. Além disso, o número de participantes deste segundo centro de convivência foi bem maior que o do primeiro; quarenta e vinte participantes respectivamente. Enquanto o estímulo à memória de plantas e história dos terrários alinhavou a interação no início das oficinas, a maior parte das dúvidas, que eram sobre como manter tais construções; conceberam como momento-chave os temas finitude e o curso da vida.

Não houve uma conversa com as instituições após os encontros. Este relato se refere a impressões que tive, articuladas a reflexões e possibilidades de pensar continuidades deste projeto, visto que está permeado por um contexto profissional consecutivo: de pesquisadora em e de instituições. Cabe articular essa percepção de mais à vontade como fator da oficina em ambiente com horta ao que uma pesquisa realizada em uma unidade básica de saúde informou sobre este meio: a inauguração de uma nova relação com o própria instituição e paisagem. Christiane Gasparini Araújo Costa, Mariana Tarricone Garcia, Silvana Maria Ribeiro, Marcia Fernanda de Sousa Salandini e Cláudia Maria Bógus, ao se debruçarem no vínculo entre saúde e horta informaram "[...] envolvimento dos participantes permitiu a ampliação da interação dos 
usuários entre si e com os profissionais de saúde e técnicos, constituindo-se em grupos de apoio e partilha, trocas de saberes e resgate de memórias da infância" (COSTA et al., 2015, p. 3107).

Ainda nesta perspectiva, trago as reflexões de Thaís Sampaio de Souza e Marlene Barreto Santos Miranda (2017) no que refere às influências da reforma psiquiátrica brasileira, no fim da década de 80 , na assistência: uma valorização da negociação entre sujeito, equipe e serviço. O marco, conforme as autoras, "instituiu direitos dos usuários de saúde mental e garantiu a assistência em serviços substitutivos de saúde" (DE SOUZA; MIRANDA, 2017, p. 311). Frente a esta leitura, oportuno trazer tendências do campo da saúde para tal concepção, bem como sua valorização social. A definição da Organização Mundial da Saúde de 1947, ao definir saúde como um estado de completo bem-estar físico, mental e social e não apenas a ausência de doença ou enfermidade ${ }^{10}$ se amalgama a outros marcos que ramificam a saúde como valor integrado à noção de sujeito, influenciando distintas políticas públicas, como as direcionadas para pessoas idosas. Neste sentido, os serviços substitutivos referenciados por De Souza e Miranda (2017) se relacionam, de distintas maneiras, à grandeza de valor que as áreas de lazer, terapêuticas e culturais passaram a ter também nas políticas públicas.

\section{Dos vidros para fora e com eles para dentro}

As edições de Sobre nossos quintais: confeç̧ão de terrários referenciadas foram um exercício propulsor de desnaturalizações, a contar já de desnaturalizar vínculos entre envelhecimento e plantas articulados a ambientes e trajetórias rurais; idosas e idosos que vivem em ambiente urbano, durante seu curso da vida, podem começar a se interessar e cuidar de plantas em distintas idades e contextos. Cabe não naturalizar também outros vínculos, como jardim, cidade e envelhecimento. Como um dos componentes desta vinculação não natural, cabe destacarmos a influência dos discursos em torno da saúde e do espaço que o lazer tem ganhado nas políticas públicas voltadas aos contornos do que é considerado e difundido como saudável. Tais discursos, mesmo marcadamente diversificados pelo prisma da desigualdade, têm se tornado, ao longo destas décadas, assuntos e cobranças eficazes nos e aos âmbitos privados como mostrou Guita Grin Debert (1999) ao conceituar a "reprivatização da velhice" como "processo em que seus dramas se transformam em responsabilidades dos

10 Disponível em: https://www.paho.org/hq/index.php?option=com_content\&view=article\&id=1440 1 :health-indicators-conceptual-and-operational-considerations-section-1\&ltemid=0\&lang=pt. 
indivíduos que negligenciaram seus corpos e foram incapazes de se envolver em atividades motivadoras" (DEBERT, 1999, p. 72).

Articulada a estas questões, desnaturalizar a ideia de que fora do campo as relações com as plantas são artificiais - inclusive a própria palavra, que neste caso especificamente nos mostra também um julgo de valor e diminuição - é um exercício também importante. Uma aproximação aos sentidos e usos das plantas, bem como cuidados e práticas com elas, está assim, muito mais para um observar como querer ver, reparar. Ao questionar sobre visões sociais do ambiente físico, natural e humanizado; como o percebemos, o estruturamos e avaliamos, Yi-Fu Tuan (1980, p. 288) nos mostra que "os seres humanos persistentemente têm procurado um ambiente ideal". A variação de como as apresentações deste ideal se dão em cada cultura, alargando um dos argumentos do autor, está também cada trajetória e parte de percursos de vida, bem como condições.

Tais fatores se articulam nos imaginários em torno de jardim e jardinagem, forjados socialmente também. Estão relacionados à noção de paisagem aqui referenciada; não inerme (SANTOS, 1988) e compreendida como perpetuamente em construção na perspectiva de Tim Ingolde que aproxima-se de uma tarefa proposta por este autor em entrevista à Clara Mafra (2014, p. 316) como um "falar de caminhos e movimentos, e de caminhos como movimento, ou seja, como linhas, mais do que como entidades".

Ao tratar dos jardins de Buenos Aires, Sonia Berjman (2018) nos atenta que é mais frequente conhecer os jardins públicos do que os jardins privados e indaga sobre as diferenças entre estes. Se aproximar dos jardins de instituições voltadas a grupos de idosos é estimulante nesse sentido também. Nise da Silveira (2006) ao dialogar com Ludwing Binswanger e análise existencial, recorda-nos que este autor "acentua que a experiência da espacialidade é essencialmente determinada pelo tom afetivo dominante no momento" (SILVEIRA, 2006, p. 143). Podemos expandir a atenção frente à arquitetura hospitalar que Nise da Silveira relata para outros espaços institucionais, como quando voltados a grupos de idosos, de convivência e ou moradia:

A ausência de interesse da psiquiatria pelos problemas do espaço torna-se patente na arquitetura hospitalar. É uma arquitetura feia, fria, rígida. Dá suporte e reforço ao medo, ao sentimento de estar isolado de tudo. Veja-se, por exemplo, como um esquizofrênico de Engenho de Dentro fala sobre o muro do hospital. Conversando com Vicente, jovem pesquisador do Museu de Imagens do Inconsciente, ele foi dizendo: "O muro é muito bonito para quem passa do lado de fora. É bem-feito, bem-arrumado. Mas para quem está aqui dentro é horrível. O muro não deveria ser assim, deveria ter algumas aberturas. Você vê, a entrada do hospital é enorme, mas se um de nós quiser passar por ela, para ir lá fora, 
não deixam. Olha, é verdade que do lado de dentro deste muro, que pega de esquina a esquina, tem banquinhos, árvores, para nos dias de visita os doentes ficarem lá. Mas mesmo assim todos nós somos controlados. Este muro serve para fechar a nossa vista para o lado de fora. Nós nunca podemos ser considerados gente com um muro deste tapando nossa visão" (SILVEIRA, 2006, p. 143).

Esse depoimento de um interno - do qual o nome não é trazido pela autora - da instituição em Engenho de Dentro se aproxima dessa estética de jardins institucionais ao que Erving Goffman (1985) atentou como representação para interação com uma potência impressionante. Faz recordar uma paisagem pintada por van Gogh quando institucionalizado no asilo de Saint-Remyem 1889 e traz Silva, personagem do livro A maquina de fazer espanhóis (1971), de Valter Hugo Mãe:

[...] e as putas das flores e das arvorezinhas cheias de passarinhos aos quais devíamos torcer o pescoço para nunca mais interferirem em nossas feridas profundas. Que se fodam os discursos da falsa preocupação dessa gente que sorri diante de nós mas que pensa que é assim mesmo, afinal, estamos velhos e temos de morrer, um primeiro e o outro e depois está tudo muito bem (MÃE, 1971, p. 22).

Figura 2 - Banco de pedra no asilo Saint-Remy, van Gogh, 1889.

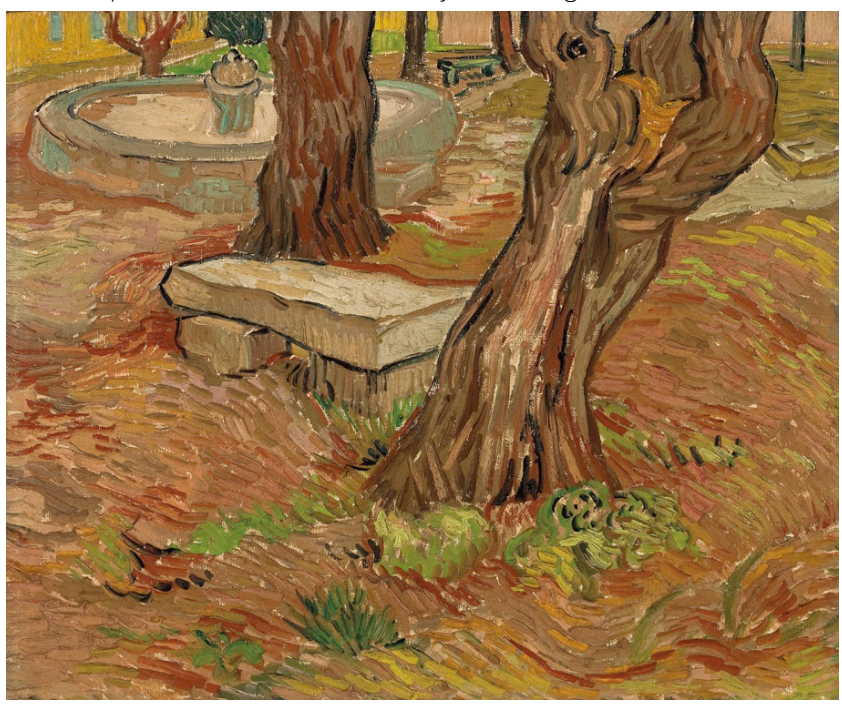

Fonte: MASP ${ }^{11}$

11 Disponível em: https://masp.org.br/acervo/obra/banco-de-pedra-no-asilo-de-saint-remy. Acesso em: 13 de setembro de 2020. 
Evidentemente que o jardim e seus elementos realçam um cenário representacional harmônico em instituições, evidenciados criticamente por Silva de acordo com seu imaginário. Longe de firmar pacto com essa condição harmoniosa, mas ao levar em conta imaginários outros, bem como os cuidados direcionadas às plantas observados entre moradoras de instituições para pessoas idosas em situação de rua, as relações com as plantas em instituições puderam remeter em meu olhar uma perspectiva que considera distintos vínculos e distintas possibilidades; podem estar permeados por lembranças, processos de continuidade e novas relações diante do contexto de moradia e ou convivência. Entretanto, nesses três relatos/cena - a de engenho de Dentro, olhar de van Gogh e Silva - remontam de maneira interessante e temporalmente diferentes afeições possíveis com paisagens verdes institucionais.

É aqui também que o entrecruzamento de arquitetura e jardim, o paisagismo - enquanto ação de intervenção planejada sobre a paisagem -, informa sua importância. A contar da frequência dos jardins em instituições voltadas ao público idoso - mesmo com intensidades diferentes - para um olhar multidisciplinar, tal presença pode ser estimulada e transformada também em importância e atenção no que refere ao traço de aproximações de atividades voltadas às áreas de arteterapia, horticultura, jardinagem e gerontologia. Neste sentindo, tal entrecruzamento de perspectivas nesses ambientes é uma possibilidade de usufruir e constituir estes espaços. Essa vivência do espaço pode se dar em duas medidas e articuladas: entrecruzado ao "aqui e agora" (FABIETTI, 2004) no que refere à arteterapia e a partir da vinculação de memória, afeto e planta por cada participante com as práticas de jardinagem. É ainda nesta constelação de relações que os terrários são um fazer-chave entre arte e jardinagem. 
Figura 3 - Oficina sobre nossos quintais: confecção de terrários.

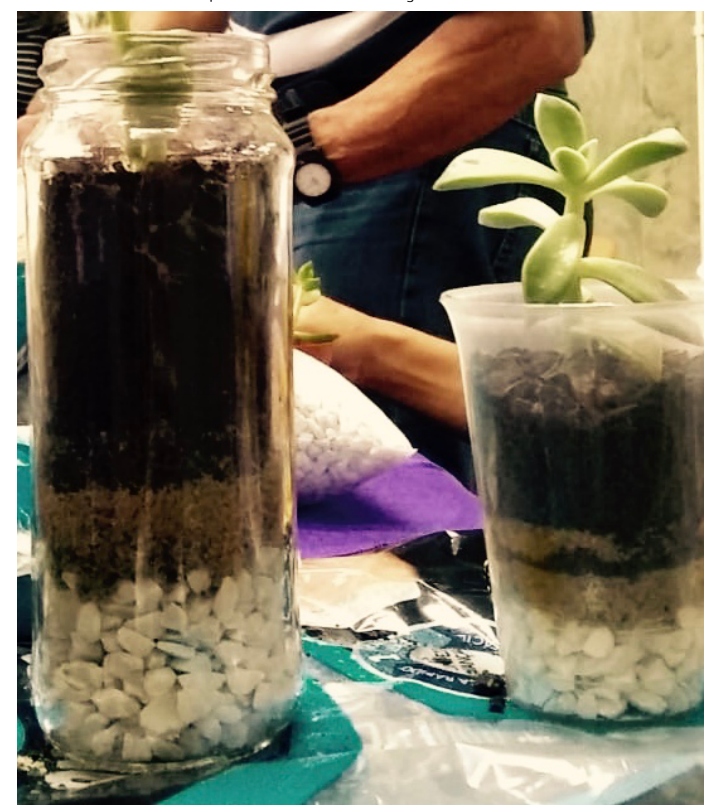

Foto: Natalia Negretti.

\section{Considerações}

Da mesma maneira que uma muda de planta pode ser recebida em diferentes solos com diversas interações, a jardinagem pode fazer com que o sujeito crie também novos significados de plantas e sua relação com atividades em torno delas, extrapolando, portanto, o lazer e alcançando a esfera da identidade e valores subjetivos com poder de criação nos sentidos trazidos por Fabietti (2004), potência de arteterapia. A construção social da realidade opera também alicerçada na subjetividade, desde o olhar frente ao real. Tendo as oficinas como base prática e reflexão teórica, uma aproximação de relações e possibilidades de estímulos de atenção em espaços voltados ao público idoso sugere a importância de um paisagismo, que pode ser feito de acordo com as distintas realidades econômicas, visto que a paisagem verde institucional constitui um marcador comum em instituições e, em tais encontros, mostrou-se propulsora de relações possíveis com e em cada convivente com as plantas.

Quando há presença de jardins o estímulo da jardinagem pode ser um caminho possível; quando não há, existem possibilidades de composição desse 
espaço com vasos. Os terrários como um fazer-chave entre arte e jardinagem em espaços que tenham ou não jardim selam a ideia de que, como desestabilizadas dicotomias, os minijardins, ao terem possibilidades simultâneas de usos e sentidos, se aproximam do que fora dito pelo cantor Tinoco, "o mesmo chão que dá vida para a natureza, também sustenta o concreto".

\author{
PLANTING CLOSENESS: TERRARIUMS, \\ GARDENS, ART THERAPY AND GERONTOLOGY
}

abstract

This text seeks to present an approximation between gerontology and gardening with the areas of art therapy and horticulture from a practical-theoretical exercise. Based on terrarium-making workshops held in two living centers for the elderly, it aims at a dual task in bringing relationships and possibilities closer together: stimulating the institution's attention to the green presence so that gardening is a possibility of free will of practice of users of such spaces and seal terrariums as a key factor between art and gardening in spaces that have or not a garden.

keywords

Gerontology. Gardening. Terrariums. Horticulture. Art therapy.

referências

BERJMAN, Sonia. Historia de los jardines argentinos. Economía y viveros. Buenos Aires, agosto 2018. Disponível em: http://www.economiayviveros.com.ar/agosto2018/ plantas_ornamentales_y_flores_de_corte-cultivos_viveros-paisajismo-jardineria-arte_ floral-1.html. Acesso em: 5 fev. 2020.

COCCIA, Emanuele. Mente e matéria ou a vida das plantas. Revista Landa, Florianópolis, v. 1, n. 2, p. 197-220, 2013. Disponível em: http://www.revistalanda. ufsc.br/PDFs/ed2/ Emanuele\%20Coccia.pdf. Acesso em: 14 set. 2020.

COCCIA, Emanuele. A vida das plantas: uma metafísica da mistura. Tradução de Fernando Scheibe. Desterro [Florianópolis]: Cultura e Barbárie, 2018. 
COSTA, Christiane Gasparini Araújo et al. Hortas comunitárias como atividade promotora de saúde: uma experiência em Unidades Básicas de Saúde. Revista Ciência \& Saúde coletiva, Rio de Janeiro, v. 20, n. 10, p. 3099-3110, out. 2015 Available from: http://www.scielo.br/scielo.php?script=sci_arttext\&pid=S1413$-81232015001003099 \&$ lng=en\&nrm=iso. Access on: 21 oct. 2020. DOl: https://doi. org/10.1590/1413-812320152010.00352015.

CUNHA, Joaquim A.; MOURÃO, Isabel; MOURA, Luisa; BRITO, L. Miguel. Horticultura social e terapêutica em cuidados geriátricos - Estudo de caso. Anais $1^{\circ}$ Colóquio Nacional Horticultura e Terapêutica. Associação Portuguesa de Horticultura (APH). ISBN: 978-972-8936-21-1. Lisboa, 2017.

DEBERT, Guita G. Velhice e o curso da vida pós-moderno. REVISTA USP, São Paulo, n. 42, p. 70-83, jun./ago. 1999.

DE SOUZA, Thaís Sampaio; MIRANDA, Marlene Barreto Santos. HORTICULTURA COMO TECNOLOGIA DE SAÚDE MENTAL. Revista Psicologia, Diversidade e Saúde, [S.I.], v. 6, n. 4, p. 310-323, nov. 2017. ISSN 2317-3394. Disponível em: https://www5. bahiana.edu.br/index.php/psicologia/article/view/1662. Acesso em: 22 out. 2020. DOl: http://dx.doi.org/10.17267/2317-3394rpds.v6i4.1662.

EVANGELISTA, Roger. Terrários: plantando criatividade e colhendo arte. São Paulo: Editora Senac São Paulo, 2019

FABIETTI, Deolinda M. C. F. Arteterapia e envelhecimento. São Paulo: Casa do Psicólogo, 2004.

FAVRET-SAADA, Jeanne. Ser afetado. São Paulo: Cadernos de Campo № 13, 2005

FRANÇA, Isadora Lins. Consumindo lugares, consumindo nos lugares: homossexualidade, consumo e produção de subjetividades na cidade de São Paulo. Tese (Doutorado em Ciências Sociais) - Instituto de Filosofia e Ciências Humanas, Universidade Estadual de Campinas, 2010.

GUERRIERO, Silas. A construção da Realidade: Imaginário, mito e religião. In: Guerriero, Silas (org.) Antropos e Psique: o outro e sua subjetividade. São Paulo: Olho D'Água, 2001.

GOFFMAN, Erving. A representação do eu na vida cotidiana. Tradução de Maria Célia Santos Raposo. Petrópolis: Vozes, 1985.

INGOLD, Tim. Pare, olhe, escute!" - um prefácio. Ponto Urbe, 3, 2008. Revista do Núcleo de Antropologia Urbana da USP. Disponível em: http://journals.openedition.org/ pontourbe/1944. Acesso em: 19 jul. 2020. DOl: https://doi.org/10.4000/pontourbe.1944.

MÃE, Valter Hugo. A máquina de fazer espanhóis. São Paulo: Cosac Naify, 2011. p. 256

MAFRA, Clara et al. A Antropologia como participante de uma grande conversa para moldar o mundo. Entrevista com Tim Ingold. Sociologia \& Antropologia, Rio de Janeiro, v. 4, n. 2, p. 303, 2014.

NEGRETTI, Natalia. Arvorecidos, ramos e brotos sob o mesmo sol: uma perspectiva em torno do envelhecimento de trabalhadores de jardins em São Paulo. Trabalho de Conclusão de Curso. Programa de Especialização de Gerontologia da Faculdade de Educação em Ciências da Saúde do Hospital Alemão Oswaldo Cruz. São Paulo, 2020. SANTOS, Milton. A Natureza do Espaço: Técnica e Tempo, Razão e Emoção. 4. ed. 2. reimpr. São Paulo: Editora da Universidade de São Paulo, 2006.

SANTOS, Milton. Metamorfoses do espaço habitado: fundamentos teórico e metodológico da geografia. São Paulo: Hucitec, 1988.

SANTOS, Milton. A responsabilidade social dos geógrafos. Raega - O Espaço Geográfico em Análise, [S.I.], v. 6, dec. 2002. ISSN: 2177-2738. Disponível em: https://revistas, ufpr.br/raega/article/view/18530/12069. Acesso em: 23 set. 2020. DOl: http://dx.doi. org/10.5380/raega.v6i0.18530. 
SEBRAE-BAHIA. Estudo de mercado agronegócio: horticultura. Serviço de Apoio às Micro e Pequenas Empresas Bahia. 2017.

SILVEIRA, Nise da. Retrospectiva de um trabalho vivido no Centro Psiquiátrico Pedro II do Rio de Janeiro. Revista Latinoamericana de Psicopatologia Fundamental. São Paulo, v. 9, n. 1, p. 138-150, mar. 2006. Available from: http://www.scielo.br/scielo. php?script=sci_arttext\&pid=S1415-47142006000100138\&lng=en\&nrm=iso. Access on: 21 sep. 2020. DOl: https://doi.org/10.1590/1415-47142006001011.

TÓTORA, Silvana. Apontamentos para uma ética do envelhecimento. Revista Kairós: Gerontologia, São Paulo, v. 11, n. 1, jan. 2008.

TUAN, Yi-fu. Topofilia. Um estudo da percepção, atitudes e valores do meio ambiente. São Paulo: DIFEL, 1980

Data de Submissão: 21/09/2020

Data de Aprovação: 23/10/2020 